13

\title{
Антиэмиссионное покрытие на основе карбида циркония
}

\author{
(C) А.А. Лисенков ${ }^{1}$, Н.З. Ветров ${ }^{2}$, Д.К. Кострин ${ }^{3}$ \\ ${ }^{1}$ Институт проблем машиноведения РАН, Санкт-Петербург \\ ${ }^{2}$ OАО „С.Е.Д.-СПб“, Санкт-Петербург \\ ${ }^{3}$ Санкт-Петербургский государственный электротехнический университет \\ „ЛЭТИ“ им. В.И. Ульянова (Ленина), Санкт-Петербург \\ E-mail: LISran@yandex.ru
}

Поступило в Редакцию 5 июля 2016 г.

Основным требованием при формировании антиэмиссионного интерметаллического соединения $\mathrm{Pt}_{3} \mathrm{Zr}$ является наличие стехиометрического слоя карбида циркония $\mathrm{ZrC}$, получаемого с помощью вакуумно-дугового источника плазмы. Показана возможность получения покрытия $\mathrm{ZrC}$ в процессе отжига в вакууме многослоевого покрытия, состоящего из последовательно напыленных из плазмы вакуумно-дугового разряда нанослоев циркония $(\mathrm{Zr})$, карбида циркония переменного состава $\left(\mathrm{ZrC}_{1-x}\right)$ и карбида циркония с избыточным содержанием углеродной фазы $(\mathrm{ZrC}+\mathrm{C})$.

DOI: 10.21883/PJTF.2017.08.44535.16399

Наряду с созданием эффективных эмиттерных систем разрабатываются системы, предназначенные для устранения или подавления паразитной термоэлектронной эмиссии с сеточных электродов, возникающей, например, в вакуумных электронных приборах при высоких эксплуатационных температурах. Данная проблема весьма актуальна при создании генераторных ламп с уровнем выходной мощности, превышающей сотни $\mathrm{kW}$. В этом случае норма паразитной термоэлектронной эмиссии для большинства типов таких приборов с экранирующим сеточным электродом составляет $10^{-5} \mathrm{~A} / \mathrm{cm}^{2}$.

Молибденовый или вольфрамовый сеточный электрод, располагающийся непосредственно в зоне электронного потока и вблизи от вольфрамового торированно-карбидированного катода с рабочей температурой $2100 \mathrm{~K}$, должен обеспечивать высокое тепловое рассеивание и обладать малым коэффициентом вторичной эмиссии [1]. 
С этой целью поверхность, способную создавать паразитную термоэлектронную эмиссию, покрывают специальными антиэмиссионными покрытиями, состоящими из сложных многослойных структур различных химических соединений [2,3].

В [4] показано, что для мощных генераторных ламп с экранирующим сеточным электродом основные решения сводятся к использованию антиэмиссионных покрытий с оконечным слоем платины, обладающей высокой работой выхода и способной связывать распыляющийся в процессе работы с поверхности термоэмиссионного катода торий, образуя с ним химические соединения ThPt.

Наиболее эффективным антиэмиссионным покрытием является интерметаллид платиновой группы - $\mathrm{Pt}_{3} \mathrm{Zr}$ [5], синтезируемый при диффузионном отжиге в вакууме на тугоплавкой подложке (Mo, W) при наличии слоев карбида циркония $(\mathrm{ZrC})$ и платины $(\mathrm{Pt})$

$$
\begin{aligned}
& \mathrm{Me}_{\text {sub }}+(\mathrm{ZrC}+\mathrm{Pt})_{\text {coat }} \stackrel{T}{\rightarrow}\left\{\mathrm{Me}_{\text {sub }}+[(\mathrm{Zr}+\mathrm{C})+\mathrm{Pt}]_{\text {coat }}\right\} \\
& \stackrel{T}{\rightarrow}(\mathrm{Me}+\mathrm{MeC})_{\text {sub }}+\left(\mathrm{Pt}_{x} \mathrm{Zr}_{y}+\mathrm{C}\right)_{\text {coat }} .
\end{aligned}
$$

Основным требованием при образовании интерметаллического соединения $\mathrm{Pt}_{3} \mathrm{Zr}$ является наличие хорошо сформированного, структурированного слоя карбида циркония, получаемого с помощью вакуумнодуговых источников плазмы.

В связи с этим задачей данной работы являлась разработка технологии получения антиэмиссионного интерметаллического покрытия $\mathrm{Pt}_{3} \mathrm{Zr}$ на основе карбида циркония стехиометрического состава, формируемого в процессе управляемого плазмохимического синтеза в вакуумнодуговом источнике плазмы.

Для осуществления плазмохимического синтеза карбидных соединений в плазменный поток, генерируемый вакуумно-дуговым разрядом, вводится углеродосодержащий газ. Диссоциация молекул углеводорода протекает как за счет соударений с заряженными частицами плазменного потока, так и за счет термического разложения молекул. При этих условиях молекула становится термодинамически неустойчивой и распадается на фрагменты с меньшим количеством атомов (радикалы) и отдельные атомы. Чем меньше атомов водорода содержится в молекуле углеводорода, тем легче протекает процесс расщепления [6].

Письма в ЖТФ, 2017, том 43, вып. 8 
Количество образующихся $\mathrm{CH}_{x}$-радикалов и скорость их образования определяются соотношением энергий разрыва связей $\mathrm{C}-\mathrm{C}$ и $\mathrm{C}-\mathrm{H}$.

Для активизации процесса плазмохимического синтеза используют углеводороды с высоким отношением С:Н. Оптимальные условия для синтеза карбида циркония достигались при использовании паров бензола $\left(\mathrm{C}_{6} \mathrm{H}_{6}\right.$ - ароматический углеводород, содержащий устойчивые циклические группы атомов с замкнутой системой сопряженных связей, с наименьшим первым потенциалом ионизации $\left.U_{i 1}=9.24 \mathrm{eV}\right)$, термические превращения которого начинаются с температуры $800 \mathrm{~K}$.

Контроль за характером протекающих плазмохимических реакций и анализ состава плазменного потока осуществлялись с помощью разработанного и встроенного в вакуумную камеру эмиссионного спектрального анализатора, изготовленного на базе модернизированной одномерной ПЗС-линейки, имеющей 3648 pixels размером $8 \times 200 \mu \mathrm{m}$ [7]. Исследуемый диапазон излучения $220-950 \mathrm{~nm}$, разрешение $1.5 \mathrm{~nm}$, время записи спектра $0.01-10 \mathrm{~s}$.

Эффективность плазмохимических реакций определяется кинетической энергией частиц и составом плазменного потока. На спектрограммах отмечались линии нейтральных атомов циркония $(\mathrm{Zr})$ и углерода $(\mathrm{C})$, возбужденных атомов $\left(\mathrm{Zr}^{*}\right)$ и $\left(\mathrm{C}^{*}\right)$, а также одно- и двузарядных ионов $\left(\mathrm{Zr}^{+}, \mathrm{Zr}^{++}\right)$и $\left(\mathrm{C}^{+}, \mathrm{C}^{++}\right)$. Повышение энергии ионов, бомбардирующих поверхность конденсации, позволяет модифицировать поверхностный слой и увеличивает диффузионную подвижность адатомов по поверхности, обусловливая тем самым преимущественный рост кристаллитов в плоскости конденсации.

Основной технологической задачей при синтезе $\mathrm{ZrC}$ является согласование поступающих на подложку потоков металлических ионов материала катода $\left(d n_{\mathrm{Zii}} / d t\right)$, вычисляемых через ток дугового разряда $\left(I_{a r c}\right)$, и атомов углерода $\left(d n_{\mathrm{C}} / d t\right)$. Одновременно с этим синтез покрытия протекает на фоне разложения исходных молекул углеводорода и его радикалов непосредственно на разогретой подложке $\left(T_{s u b}=800 \mathrm{~K}\right)$, что приводит к конденсации углерода в атомарном состоянии и дополнительному науглероживанию приповерхностных областей [8], что оказывает влияние на структуру формируемого карбида.

Стехиометрическое покрытие карбида циркония получается в результате диффузионного отжига в вакууме многослоевого покрытия, состоящего из последовательно напыленных нанослоев циркония $(\mathrm{Zr})$, нестехиометрического карбида циркония переменного состава с дефи-

Письма в ЖТФ, 2017, том 43, вып. 8 

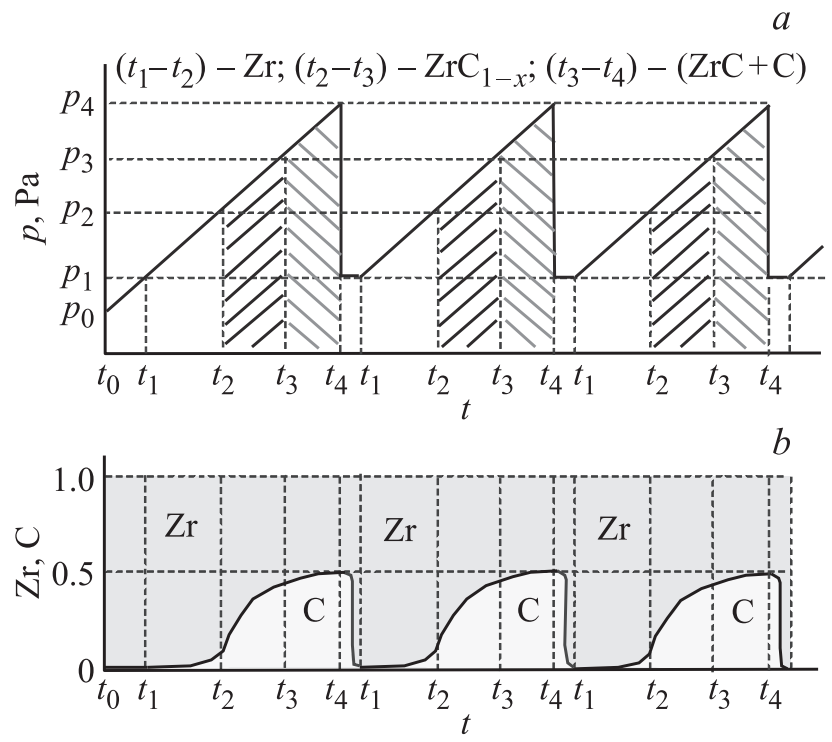

Рис. 1. Характер изменения давления в рабочем объеме $(a)$ и распределение концентрации элементов по толщине формируемых слоев $(b)$.

цитом углерода $\left(\mathrm{ZrC}_{1-x}\right)$ и карбида циркония с избыточным содержанием углеродной фазы $(\mathrm{ZrC}+\mathrm{C})$.

Осаждение нанослоев происходит на предварительно сформированный слой карбида материала подложки $\left(\mathrm{Mo}_{2} \mathrm{C}-\mathrm{MoC}\right)$, обеспечивающий создание одного из барьерных слоев, препятствующего диффузии платины в керн материала сетки, и уменьшающий наличие свободного молибдена в приповерхностном слое, что затрудняет его свободную диффузию в интерметаллический слой [9].

Напыление подслоя циркония позволяет за счет высокоэнергетических ионов циркония и одновременной диффузии атомов, осаждающихся на границе поверхностного раздела подложка-покрытие $(\mathrm{MoC}-\mathrm{Zr})$, образовать переходный барьерный слой, представляющий собой комбинацию фаз $\left(\mathrm{Mo}-\mathrm{Mo}_{2} \mathrm{C}-\mathrm{MoC}\right)-(\mathrm{MoC}-\mathrm{C}-\mathrm{Zr})$.

Последовательный набор нанослоев, осаждаемых из потока металлической плазмы вакуумно-дугового разряда, формируется за счет

Письма в ЖТФ, 2017, том 43, вып. 8 
изменения давления реакционного газа в рабочем объеме по линейному закону $(d p / d t)$, в задаваемых пределах от минимального $\left(p_{1}\right)$ до максимального $\left(p_{4}\right)$ значения (рис. $\left.1, a\right)$. Давление в рабочем объеме изменяется за один импульс открытия системы подачи рабочего газа, управляемого программным устройством, считывающим результаты измерения вакуума с ионизационного датчика.

В интервале давлений $p_{0}-p_{1}-p_{2}$ (ниже $8.7 \cdot 10^{-3}-3.3 \cdot 10^{-2}-$ $\left.4.5 \cdot 10^{-2} \mathrm{~Pa}\right)$ покрытие, осаждаемое из потока металлической плазмы, формируется из ионов и атомов циркония (рис. 1, $a$ ), распыляемого катодным пятном вакуумно-дугового разряда.

Увеличение концентрации активных реагентов $\left(\mathrm{C}_{6} \mathrm{H}_{6}\right)$ в рабочем объеме в диапазоне давлений $p_{2}-p_{3}$ изменяет фазовый состав плазменного потока и обеспечиваются условия для возникновения и протекания процесса плазмохимического синтеза соединения с образованием карбида циркония переменного состава с дефицитом углерода $\left(\mathrm{ZrC}_{1-x}\right.$, рис. $1, b)$. Формируемый карбид циркония обладает широкой областью гомогенности $\left(\mathrm{ZrC}_{0.62}-\mathrm{ZrC}_{1.0}\right)$, в пределах которой внедрение углерода в кристаллическую структуру покрытия происходит без образования новых фаз.

Слой карбида циркония с повышенным содержанием углеродной фазы в покрытии $((\mathrm{ZrC}+\mathrm{C})$, рис. $1, b)$ формируется при давлении от $p_{3}$ до $p_{4}$ (от $4.5 \cdot 10^{-2} \mathrm{~Pa}$ и выше), после чего, при достижении установленного давления $p_{4}$, подача газа прекращается и обеспечивается его удаление из рабочего объема до заданного давления $p_{1}$.

Свойства получаемых тонких слоев существенно отличаются от аналогичных характеристик монослоя, что обусловлено процессами, происходящими во время образования многосвязной внутренней структуры [10]. Получаемое многослоевое покрытие переменного состава состоит из последовательно напыленных слоев $n\left[(\mathrm{Zr})-\left(\mathrm{ZrC}_{1-x}\right)-(\mathrm{ZrC}+\mathrm{C})\right]$, в составе которых при изменяюшемся распределении концентрации углерода по толщине количество осаждаемого циркония остается постоянным ( $I_{\text {arc }}=$ const, $U_{\text {bias }}=$ const). Распределение концентрации элементов по толщине формируемых слоев представлено на рис. $1, b$.

При формировании многослоевого покрытия длительность и частота следования импульсов выбираются из условий работы системы получения вакуума. Общая толщина покрытия составляла 5-6

Письма в ЖТФ, 2017, том 43, вып. 8 


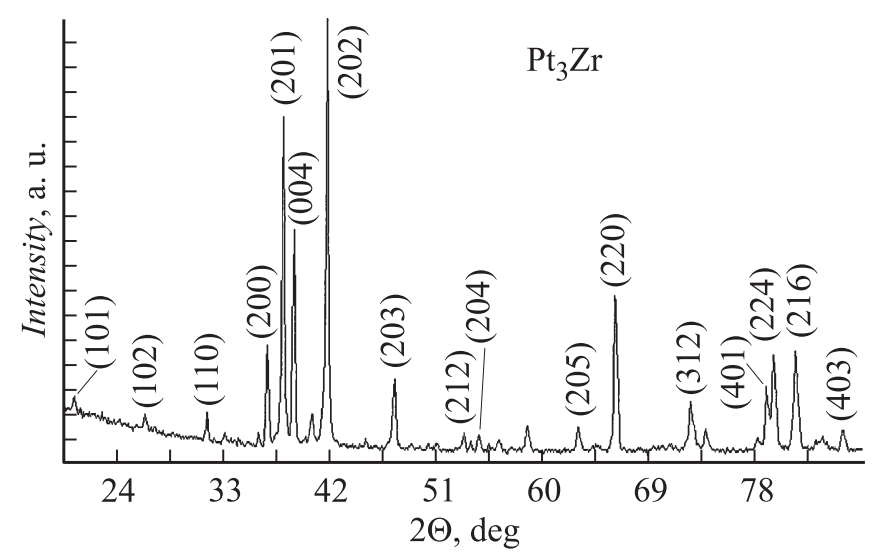

Рис. 2. Дифрактограмма интерметаллического покрытия $\mathrm{Pt}_{3} \mathrm{Zr}$ на молибденовой основе.

время напыления 50-60 min, ток разряда $I_{a r c}=75-90$ А, напряжение смещения на подложке $U_{\text {bias }}=-(100-150) \mathrm{V}$.

Согласно атомной теории, при химико-термической обработке в вакууме покрытия, состоящего из системы нанослоев переменного состава $n\left[(\mathrm{Zr})-\left(\mathrm{ZrC}_{1-x}\right)-(\mathrm{ZrC}+\mathrm{C})\right]$, из зон, насыщенных углеродом, в слои с преобладанием свободного циркония активно протекают высокотемпературные диффузионные процессы, приводящие к химической реакции с образованием стехиометрического карбида циркония по следующей схеме:

$$
\begin{gathered}
\mathrm{Mo}+\left[\left(\mathrm{Mo}_{2} \mathrm{C}+\mathrm{MoC}\right)+\mathrm{Zr}\right]+n\left[\mathrm{Zr}+\left(\mathrm{ZrC}_{1-x}\right)+(\mathrm{ZrC}+\mathrm{C})\right] \rightarrow \\
\mathrm{Mo}+[\mathrm{MoC}+\mathrm{ZrC}+\mathrm{C}]+[\mathrm{ZrC}] .
\end{gathered}
$$

Фазовый состав формируемых покрытий изучался методом рентгенофазного анализа на рентгеновском дифрактометре ДРОН-3 в фильтрованном излучении $\mathrm{Cu} K_{\alpha}$. Элементный состав покрытий определялся электронно-зондовым микроанализом, основанным на сравнении характеристических рентгеновских спектров анализируемого образца со стандартами известного состава. Толщина покрытий контролировалась с помощью шлифов. Для анализа покрытий использовались растровый 
электронный микроскоп JSM-35CF, рентгеновский микроанализатор энергодисперсионного типа Link 860 и установка катодного напыления JFC-1100.

В результате исследований было получено, что формируемое покрытие карбида циркония $(\mathrm{ZrC})$ имело хорошо сформированную кристаллическую структуру с преимущественной ориентацией (111). Из наблюдаемых линий на дифрактограммах присутствовали все основные линии, характерные для $\mathrm{ZrC}:$ (200), (220), (311), (222).

Далее, на сформированное покрытие $\mathrm{ZrC}$ в электролитическом растворе на основе платинохлористоводородной кислоты $\left(\mathrm{H}_{2}\left[\mathrm{PtCl}_{6}\right] \cdot 6 \mathrm{H}_{2} \mathrm{O}\right)$ осаждался слой платины толщиной до $10 \mu \mathrm{m}$. При последующей термической обработке $\left(T_{\text {annealing }}=1400-1700 \mathrm{~K}\right)$ в результате структурных превращений в полученной системе $(\mathrm{Mo}-\mathrm{MoC})-[(\mathrm{ZrC})-(\mathrm{Pt})]$ происходит химическое взаимодействие элементов с образованием интерметаллического соединения $\mathrm{Pt}_{3} \mathrm{Zr}$. Одна из

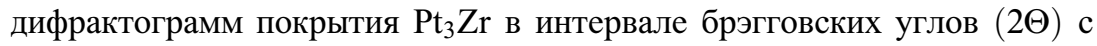
зарегистрированными линиями (200), (201), (004), (202), (203), (122), (204), (205), (206), (224) представлена на рис. 2.

Таким образом, предлагаемая технология с использованием предварительно сформированного многослоевого покрытия $n[(\mathrm{Zr})-$ $\left.\left(\mathrm{ZrC}_{1-x}\right)-(\mathrm{ZrC}+\mathrm{C})\right]$ и последующего отжига в вакууме позволяет получить стехиометрическое покрытие $\mathrm{ZrC}$ и высококачественное интерметаллическое соединение $\mathrm{Pt}_{3} \mathrm{Zr}$ и тем самым обеспечить заданные эксплуатационные свойства антиэмиссионных покрытий.

Работа выполнена в рамках проектной части государственного задания в сфере научной деятельности по заданию № 8.2456.2014/К.

\section{Список литературы}

[1] Прилуцкий В.С. Вольфрамовый торированный карбидированный катод. М.: Руда и металлы, 2001. 152 с.

[2] Li T., Feng T., Jiang B. et al. // Phys. Stat. Solidi C. 2012. N 9. P. 32-35.

[3] Jiang J., Jiang B., Ren C. et al. // J. Appl. Phys. 2005. V. 97. P. 094918.

[4] Bystrov Yu.A., Vetrov N.Z., Lisenkov A.A. // Tech. Phys. Lett. 2009. V. 35. N 7. P. $618-621$.

[5] Bystrov Yu.A., Vetrov N.Z., Lisenkov A.A. // Tech. Phys. Lett. 2010. V. 36. N 6. P. $570-573$.

Письма в ЖТФ, 2017, том 43, вып. 8 
[6] Кириков А.В., Рыжиков В.В., Суслов А.И. // Письма в ЖТФ. 1999. Т. 25. B. 19. C. $82-86$.

[7] Uhov A.A., Gerasimov V.A., Kostrin D.K., Selivanov L.M. // J. Phys.: Conf. Ser. 2014. V. 567. P. 012039.

[8] Галь Н.Р., Рутьков Е.В., Тонтегоде А.Я. // ЖТФ. 2002. Т. 72. В. 4. С. 113 119.

[9] Bystrov Yu.A., Vetrov N.Z., Lisenkov A.A. // Tech. Phys. Lett. 2013. V. 39. N 10. P. 914-916.

[10] Погребняк А.Д., Береснев В.М., Каверина А. и др. // Письма в ЖТФ. 2013. T. 39. B. 4. C. $9-16$. 